\title{
A diáspora do corpo em crise: do teatro japonês aos novos processos de comunicação do ator contemporâneo
}

\author{
Christine Greiner
}

segunda metade dos anos 1990 foi marcada por algumas discussóes importantes referentes ao corpo do artista. Algumas das propostas ajudam não apenas a elaborar uma história e uma fundamentação teórica para o corpo, mas sugerem mudanças importantes de procedimento para testar as relaçóes entre corpo e ambiente, entre corpo e outros corpos; e entre diferentes universos de conhecimento. Neste sentido, interessa a todos: atores, diretores, dançarinos, coreógrafos, performers, web artistas e assim por diante.

De todas as pesquisas que vêm sendo desenvolvidas nessa área, gostaria de destacar uma que particularmente me intriga e está voltada ao estudo do corpo em crise - um ambiente onde a contaminação entre o dentro e o fora parece chegar às últimas conseqüências, exigindo novas abordagens para ser melhor compreendida.

Este artigo é, portanto, uma espécie de primeiro rascunho de pensamentos que têm me atormentado há alguns anos e que, aos poucos, começam a ser sistematizados, partindo da idéia de que o corpo não é algo pronto, um compartimento de idéias, um instrumento de alguma 'outra coisa' ou um meio inscrito pelas informações que correm mundo afora e aí se deleitam, na paisagem inóspita que as abriga. Antes de entrar no exemplo japonês, que é de onde surge o conceito de corpo em crise que pretendo discutir, vou comentar algumas publicaçôes de autores ocidentais que ajudam a iluminar a questão, partindo de pesquisas nas áreas da dança, da cultura e das Ciências Cognitivas.

\section{Corpo-realidades e \\ a perversidade das ações}

Uma das primeiras pesquisas que me chamou a atenção, em 1996, foi Corporealities, dancing knowledge, culture and power, editada pela crítica de dança Susan Leigh Foster (1996). A proposta parecia clara: estudar a realidade corporal não como algo dado, natural e absoluto, mas como "uma categoria substancial da experiência cultural”. A idéia era recusar o postulado de que o corpo segue necessariamente em direção a outros campos de significado e, ao mesmo tempo, reconhecer que ele tem mobilidade física e articulação, o que o impede de permanecer enclausurado em si mesmo. Parecia um paradoxo e por isso pedia por uma rede complexa de relações, ou seja, tornava-se insuficiente elencar as técnicas de dança já mapeadas para explicar o movimento dos corpos. A idéia era abandonar por um momento as amarras do raciocínio seqüencial

Christine Greiner é professora do Programa de Estudos Pós-Graduados em Comunicação e Semiótica da Pontifícia Universidade Católica de São Paulo. 
da ordem cronológica para o que seria observar o corpo à luz de disciplinas como a etnologia, a historiografia, o materialismo dialético, a psicanálise e a hermenêutica. $\mathrm{Na}$ verdade, tratava-se de pensar como teorias poderiam auxiliar no mapeamento corporal, no caso específico da dança, usando o pensamento da dança e o pensamento coreográfico para estudar desenvolvimentos de linguagem.

Tal iniciativa de pesquisar o que Foster chamou de "corpo-realidades" passou a tratar, portanto, a coreografia como uma teorização de relações entre corpo e self, gênero, desejo, individualidade e nacionalidade. Pensava-se não mais apenas no corpo, mas acerca do "escrever sobre o corpo", revendo categorias previamente estáveis do conhecimento. Nesse viés, teoria e prática passariam a caminhar juntas. Mais uma vez, discutia-se a perenidade da dança, chamando-se a atenção para a possibilidade de fixar e tornar seguro algo que sempre se revela no momento em que desaparece. Mas qual o traço que fica? O que é observável? Isso teria uma relação com a escolha da informação a ser internalizada no trânsito entre corpo e ambiente?

Tópicos que também têm sido trabalhados são o do deslocamento e do desaparecimento. Nesses estudos, é possível identificar uma contaminação entre os estudos da dança e os da performance, uma vez que essas estratégias auxiliariam a composição e a interpretação da prática contemporânea. Haveria uma relação com a repetição como ato filosófico e de significação, indagando o que é perceber/identificar o movimento. Há alguns anos, já não havia mais sentido discutir um suposto 'movimento original'. Mesmo no que se refere ao corpo 'ele mesmo', o movimento é sempre algo que está em processo. Não é uno, original, primeiro. As imagens refletem, em seu estado de cegueira, a própria ausência. Fala-se em uma discussão sobre a experiência visual que nunca é totalmente organizada por um ego central, um sujeito apartado do mundo onde está.

$\mathrm{Na}$ história da arte, o trompe l'oeil com a proliferação de traços fragmentados, distor- cidos, sem o controle do sujeito, com o uso do acaso, já chamava a atenção para essa possibilidade do reconhecimento de um real, daquilo que teria existência a despeito do nosso conhecimento. $\mathrm{O}$ ambiente faz-se presente e não é só um espaço onde o corpo está, mas um parceiro da performance. Freud falava em entstellung (distorção), que não significaria apenas desfigurar, mas deslocar. Não só mudar a aparência de algo, mas colocar algo em outro lugar. $\mathrm{O}$ ato de perceber alguma coisa já incitava, portanto, o seu próprio deslocamento. Quando move, algo vai para outro lugar como deslocamento do corpo (e no corpo). No ato de interpretar o movimento, haveria o deslocamento do deslocamento. Nesse sentido, a repetição tornava-se uma impossibilidade. Ao mesmo tempo, era uma estratégia que chamava a atenção para o desaparecimento. Freud explorou também a repetição ligada ao trauma. Um indivíduo, através da repetição de uma experiência traumática, poderia tomar parte ativamente de uma relação com o evento 're-presentando-o' como performance. $\mathrm{O}$ desaparecimento, paradoxalmente, manifestaria o que se presume ausente. Dá existência não apenas à aparência, mas à percepção, à apreensão, à experiência e à memória. Esquecer um evento permite experimentá-lo pela primeira vez, evidentemente, como um novo evento, um novo estado do corpo. Se a saída do movimento preserva o movimento e se a história nunca pode ser capturada, então o aspecto fundamental da performance é existir através do seu desaparecimento. É o que a torna possível em sua impossibilidade. Com a dança não seria diferente.

Uma outra publicação interessante que revisa o tema corpo e organiza uma discussão similar é Re-membering the Body, de Gabriele Brandstetter (2000), um livro que é, simultaneamente, uma exposição e uma série de apresentações cênicas. A proposta é partir dos discursos da arte, das ciências e da mídia. O corpo conteria uma multiplicidade de corpos e conceitos disponíveis na sociedade moderna. Algumas regras de codificação marcariam a escolha e o arranjo de signos incorporados. $\mathrm{O}$ que interessa 
é indagar os aparatos dessa corporificação, ou seja, como um corpo torna-se corpo e os muitos corpos do corpo. Os pais do período moderno, Baudelaire, Nietzsche, Proust e Valéry, viram o movimento como corolário das novas tecnologias e mídias. O cinema expôs, de certa forma, o paradoxo do movimento, o intercâmbio entre a permanência e o movimento, a imagem do corpo e a simulação do movimento. $\mathrm{Na}$ obra de artistas como Meg Stuart, William Forsythe e outros, a preocupação é com a questão da representação, que não pressupõe o corpo, suas imagens e escritos como dados, mas postula o corpo como uma hipótese e, segundo Brandstetter, orquestra as formas na sua dissolução. Forsythe chega a dizer que na dança, o corpo existe apenas na forma temporal. A ocorrência da performance do corpo evade qualquer tentativa de tradução no sentido de se 'decifrar algo', de 'revelar'. Relaciona-se, isso sim, ao tema da memória do corpo e do movimento com o processo concomitante de lembrar e esquecer. Nada além do que uma seleção contínua de informação que se auto-organiza o tempo todo. As imagens lembradas e os traços da história do corpo são sempre partes e fragmentos que se compóem de modos diferentes.

São feitos três recortes:

1) o corpo como topografia;

2) o corpo como mídia;

3) o corpo como temporalidade.

$\mathrm{O}$ que restaura o corpo são as imagens relembradas que, de certa forma, também o relembram como figura da temporalidade. Um bom exemplo é o do Egito Antigo. Lá, o centro da atenção não era o corpo vivo, mas o corpo criado depois da morte através de processos que o embalsamavam para uma forma final. O corpo era formatado, membro a membro, tornando-se imortal. A reintegração dos membros nessa forma final era acompanhada por textos metafóricos. Os membros eram nomeados individualmente de forma litúrgica e colocados juntos em um corpo lingüístico, eternizado como um texto de deificação. Todos os textos virtuais da linguagem trabalhavam com formas simbólicas e transformavam-se em figuras da linguagem da eternidade.

No maneirismo (1520-1620) e no final do Renascimento, a representação do corpo rompe com as proporções clássicas e a organização do espaço provoca uma espécie de distorção, seguindo um padrão de movimento orientado de percepção. Falava-se em anamorfose, a dissolução da composição pictórica estática baseada na perspectiva. Isso mudava o foco de observação. A anamorfose revelava um princípio composicional teatral, criando um espaço de movimento dentro do quadro. A percepção de estruturas dos tempos modernos trabalhava conceitos de separação e de transferência. Isso reaparece no século $\mathrm{XX}$, nas experiências para criar seres híbridos entre homens e máquinas, por exemplo, na forma de cyborg, assim como nas transcriçõos e representações do que ficou conhecido como a periodicidade do movimento. Isso persiste nas experiências de Nietzsche, que falava em retornos rítmicos e no princípio poético, assim como nas investigações científicas do movimento até 1850 . Remonta também aos primórdios do cinema, onde se repetiam figuras que tinham aptidão para o movimento. Há uma relação com duas investigações distantes no tempo, mas que têm uma conexão clara: o ensaio antológico de Heinrich Von Kleist ( $D a$ vida das marionetes) e os novos corpos virtuais. Assim como as marionetes são suspensas por cordas e não se submetem às leis da gravidade, os corpos virtuais também simulam o desequilíbrio ou o equilíbrio em novos ambientes. Algo que, avant la lettre, começava a despontar no cinema com a relação entre corpo em movimento e movimento da câmera. A questão era então como escanear um corpo, representá-lo em outro ambiente, aqui entendido sempre como uma complexa rede de informações, e não um lugar.

O filósofo Jean-Luc Nancy reconheceria, em sua obra Corpus (2000), o corpo presentificado, que tem uma existência singular e modula variantes (pintura, ensaio, literatura, pranchas de Vesalius ou de Leonardo, relatos freudianos acerca da histeria). O corpo é invariavelmente 
um corpo inventado. As suas escrituras ora são visíveis, tatuadas, cicatrizadas, ora apenas movimentos. O corpo é um lugar de existência. Não é cheio nem vazio, nem dentro, nem fora, não tem partes nem totalidade, nem funções, nem finalidade. Não se discute a morte ou a vida, não há essências a serem levadas a sério. $\mathrm{O}$ que existe é o espaço mortal do corpo. Um fantasma do espaço abolido. A idéia de ego como uma ocorrência está ligada ao que Nancy chamará de "corpus ego". Isso quer dizer que corpus não é mais um discurso, mas uma possibilidade de ação. O dentro do corpo são operações específicas como sensações e percepções. Tomando o exemplo da meditação, o filósofo explica que a experiência é sentar no chão. Tudo é o gesto. A nudez desse gesto radical é o que faz do budismo, o budismo. Não é para ficar imaginando coisas, nem mesmo o nada. Há uma tendência espontânea em direção a padrões mentais estáveis que são repetitivos e isso nada mais é do que a vida cotidiana. A introspecção busca o que se sabe fazer. Não se pode mais falar em termos de dentro e fora como instâncias absolutamente separadas, mas sim de propriedades e qualidades descritivas. Portanto, é preciso estabelecer regras. Novas regras. Pergunta-se: é possível importar essas regras de um domínio para outro? O corpo em crise está relacionado a este cruzamento de domínios?

A última referência que preciso para alinhavar esses pensamentos é o ateliê de 1997, organizado pela coreógrafa Susan Buirge, que investigava os trânsitos nos processos de composição em arte contemporânea, buscando criar pontes entre artistas visuais e dançarinos. A sua questão era como dançarinos descobriram procedimentos elaborados em outros campos a partir de questionamentos expressivos, filosóficos e que cruzavam os meios por onde se inscreviam. A princípio, os isomorfismos pareciam verdadeiros mistérios. A idéia de uma sintaxe generalizada que pudesse se propagar de uma prática a outra tornava-se um desafio e não era uma tarefa nada fácil. Partia da hipótese de que um gesto ou um som poderia traçar o seu pró- prio caminho, na busca de familiaridades. Julia Kristeva, partindo de uma visão antropológica alimentada também pela lingüística e pela psicanálise, mencionava o conceito de uma mobilidade originária do pulsional que decupava o texto como uma espécie de transporte de energias pulsionais, organizando um espaço onde o sujeito não podia mais ser reconhecido como uma "unidade crivada". Tudo era entendido em processo, como operações fundadas nos modos de representação. As operações de base (cruzar, reencontrar, avançar, entre outras) buscavam o que se chamava de dramaturgia primitiva. Já no começo do século havia uma contestação em relação à mímese, aos modos tradicionais de representação clássica, concebidos a partir de Platão e Aristóteles. Abordagens diferentes vão criar permutas entre o status do visível e do não visível, como corpos que atravessavam outros espaços de manifestação. A arte tornava-se um dispositivo revelador do invisível, traduzindo uma realidade que escapava provisoriamente $\mathrm{da}$ percepção cotidiana. As razões dessa invisibilidade podiam ser de ordens diversas. Para os expressionistas, era a necessidade interior que confinava a existência em um estado subjetivo. A criação surgia na presença desse labirinto: memória, inconsciente e imaginário. A alemã Mary Wigman é o grande exemplo. Há um fluxo de informações que emana de uma dança absoluta que provém de impressóes recentes ou antigas, invariavelmente obsessivas.

Aos poucos, vão surgindo outras possibilidades de representação. Malevitch, na arte, quando expõe a tela branca, propõe um mundo sem objetos. A arte sem objetos é uma arte em processo. Os expressionistas e futuristas também buscavam essa dinâmica invisível que excedia a figura e a sua dissolução. Marinetti dirá que o gesto que queremos reproduzir não é um instante fixado, mas a sensação dinâmica. A plástica parecia uma frase de espaço instaurada num campo de forças que precisava se comunicar com massa, volume, música interior, regime de tensóes musculares, deslocamento e duração. $\mathrm{O}$ conceito de plástica era então uma 
exteriorização do visível que vai aparecer apenas cinqüenta anos mais tarde com o performer Joseph Beuys. Para Beuys, os estados de energia interior eram a questão. Uma zona de obscuridade em relação ao universo subjetivo (Umwelt) e o território intermediário entre visível e invisível, que começava a ser explicado como visual e não visual. $\mathrm{O}$ invisível enriquecia-se através de uma outra referência quando a teoria da arte migrava para o território não-visual. Seria estudado o ato composicional que apagava, aos poucos, a hierarquia entre parte e todo. A dança criava a sua própria materialidade, sem se referir a um léxico pré-estabelecido. Não era mais possível decidir entre a anterioridade de um elemento em relação a outro. Movimentos eram unidades motoras, sem classificações hierarquizadas.

Jan Fabre também discutiria a relação com as artes plásticas, a necessidade de viver na superfície, chamando a atenção para a relação com o corpo através de um diálogo físico com o papel. O papel entendido como pele. A duração da ação ou do movimento revelava uma importância capital nas representações. $\mathrm{O}$ tempo presente era como o da partitura musical, como um desenho. Não é à toa que os insetos tornaram-se uma grande fonte de inspiração para esses artistas, uma vez que passavam por muitas metamorfoses, transformando-se a partir de larvas. Alguns tinham esqueleto externo, espécies de armadura. Alguns renasciam em um estado de pós-morte. Desenhar e esculpir eram também metamorfoses que lembravam os insetos. Desenhar sobre o próprio corpo, no corpo dos outros, com materiais diferentes: sangue, dejetos, tinta etc. A dança contemporânea, contaminada pela performance, eliminava a imagem matriz e motriz valorizando as fases intermediárias e as chamadas conexôes. O trajeto como experiência ontológica de deslocamento abandonava a idéia de vocabulário, de padrões préestabelecidos, de um mundo mapeado a priori.

\section{O corpo em tempo presente}

A perversão do dualismo cartesiano começa no século XIX, mas é com a fenomenologia, a partir dos primeiros anos do século XX, que a crítica se efetiva, no sentido de um complexo levantamento de problemas. As soluções começam a aparecer mais tarde. E muitas delas ainda sobrevivem na forma de indagações.

O primeiro filósofo a recolocar as discussões de Descartes foi provavelmente Husserl, cujos textos datam de 1907 (Ding und Raum) e 1912 (Ideias I e Ideias II). Ele não era um filósofo do corpo, mas um filósofo da consciência; não estava interessado em descrever a textura sensual da existência encarnada, mas em estabelecer a autonomia e a eficácia da razão. Nos seus esforços para embasar a razão, desenvolve uma fenomenologia do corpo, na qual a dependência do corpo marcará outros filósofos como Sartre e Merleau-Ponty.

A sua questão era como entender a relação entre a descrição científica do corpo e a caraterização fenomenológica do corpo, ou seja, o corpo atuando em tempo real. Uma saída seria observar a atitude natural e como a presença das coisas indicam a presença do corpo como corpo vivo; o modo como um fenômeno descreve um corpo vivo em seus próprios termos e como nós vemos este corpo; e indagando se o fato de vermos o corpo vivo como parte da natureza possibilita colocá-lo em relação a uma descrição objetiva.

O pensamento mais poderoso da discussão fenomenológica, identificado em praticamente todos os estudos dessa grade teórica, é relativo à preocupação com o instante presente, com o corpo no momento da ação. Evidentemente, a solução proposta por esses filósofos (Husserl, Heidegger, Merleau-Ponty e Sartre, entre outros) é filosófica, suscitando mais perguntas do que respostas. Resvala nas palavras a angústia de que qualquer tentativa de captar o real representa imediatamente a sua perda. Tal investigação passa também por outras áreas do conhecimento. Os cientistas (ver Clark, 1997) 
que vão pesquisar a teoria dinamicista para entender a ação em tempo real, indicarão soluções relativas ao funcionamento do sistema sensóriomotor, das conexões neurofisiológicas e assim por diante. A proposta será conceber ação e cognição na mesma escala temporal, questionando a noção de "base", sob a qual se estabelece todo o nosso sistema educacional, assim como dualismos do tipo teoria-prática, corpomente e o não menos famoso razão-emoção. Os performers, igualmente interessados no tempo real e na sua irreversibilidade, encontrarão no universo artístico uma espécie de solução para garantir a sua sobrevivência, lidando com o fato de que tudo é provisório, seja qual for o nível de descrição escolhido. A escolha é sempre entre a taxa maior ou menor de estabilidade que, invariavelmente, coexistirá com uma taxa maior ou menor de instabilidade. A escolha inevitável é investigar diferentes soluções, e não deixá-las compartimentadas na clausura de seus saberes.

Neste sentido, não há uma receita para entender o que seria e como se apresenta a dramaturgia do corpo em seu estado de crise. Muitas questôes estão em jogo. O tempo aparece como um dos aspectos fundamentais: tempo presente que carrega e modifica passado e futuro. Outro ponto importante é o 'mapeamento da obra'. Não se trata apenas daquilo que se vê. É no trânsito entre imagens externas e internas que as mudanças de estado do corpo são construídas. 'Identificar um mapa' não quer dizer 'vê-lo', mas sim reconhecer conexões. 'Construir um corpo' também é uma proposta que precisa ser esclarecida. O que organiza essa construção é o trânsito corpo/ambiente e não apenas a vontade do criador. Assim, quanto mais informações e ignições forem dadas durante o processo, maior a probabilidade de se testar novas combinaçôes. Esse seria o papel do dramaturgo do corpo. Nutrir o sistema, tornar complexo o processo de criação e driblar a estabilidade flexibilizando todos os limites. Nessa situação de crise (a discussão é sempre sobre o tempo), quando finalmente emerge um padrão que insiste em sobreviver, o sinal é claro: um novo pensamento está para ser instaurado no mundo.

\section{O caso japonês e \\ a genealogia do corpo em crise}

O teatro e a dança japonesa receberam maior atenção editorial no Brasil a partir dos anos 1980 , sobretudo no que se refere às manifestaçōes mais tradicionais (nô, kabuki, bunraku e kyôgen). Hoje há uma bibliografia pequena, mas suficientemente esclarecedora, para introduzir o tema aos novos estudantes e artistas interessados. Destacam-se, entre outros estudos, as obras das professoras Darci Kusano e Sakae Giroux acerca do teatro japonês.

Nos anos 1990, dois livros sobre butô (Baiocchi, 1997; Greiner, 1998) trouxeram a discussão para o contexto contemporâneo. A dissertação de mestrado de Lígia Verdi (não publicada, mas disponível nas bibliotecas da ECA, da Fundação Japão e da PUC) acerca de Ohno Kazuo é preciosa porque descreve as aulas e apresenta, na íntegra, entrevistas muito esclarecedoras. No entanto, ainda existe uma lacuna importante que vai do movimento angura (tradução japonesa do termo underground) dos anos 1960 até o shingeki, do começo do século XX e à diversidade de experiências realizadas após os anos 1980, sugerindo conexões com os quadrinhos japoneses (mangá), as novas tecnologias e muitas outras discussões do mundo contemporâneo (o mundo pós-Akira).

Para esclarecer algumas questóes acerca desses períodos, a desconstrução do suposto 'japonismo' parece fazer parte de muitas das experiências contemporâneas. Ou seja, discutir o teatro japonês contemporâneo e os trânsitos com o Ocidente, não diz mais respeito apenas aos 'temas' abordados, mas sim ao treinamento do corpo do ator, às suas relações com o ambiente e ao modo de entender a relação entre natureza e cultura. A hipótese que estou desenvolvendo busca identificar a diáspora do corpo em crise não apenas na história do teatro japonês, mas na familiaridade com o que se faz fora de 
lá, a partir de outras conexões. Hijikata Tatsumi, o criador do butô e mentor da qualidade butôsei (a qualidade da crise), acreditava que uma vez reconhecida essa instabilidade própria à natureza do corpo, a arte deixaria de ser dividida em gêneros e escolas, passando a ser organizada pela familiaridade de pensamentos, sem um carimbo de nacionalidade, determinando o que se pode ou não fazer. O limite seria conferido a partir da aptidão para criar novas conexões no chamado corpo morto. O corpo capaz de renascer como o receptáculo do ambiente onde está.

No Japão, o shingeki foi um dos primeiros movimentos teatrais que buscou uma proximidade com o Ocidente. Os pioneiros do movimento anterior (shimpa) estavam mais voltados para uma espécie de sensacionalismo, mesmo em seu período áureo. As peças não tinham grande valor literário e, muitas vezes, trabalhavam apenas com questões do momento, como um confronto político ou às vezes temas violentos, mas tudo em direção a uma atitude bastante comercial.

O shingeki mostrava um comprometimento diferente. Nasceu em duas grandes universidades de Tóquio (Waseda e Keiô), buscando criar um teatro moderno japonês e atuando, quase sempre, fora do circuito comercial. Os marcos foram o estabelecimento do Bungei Kyôkai (Associação Literária de 1906) por Tsubouchi Shôyô (1858-1933) em Waseda; e o Jiŷu Gekijô (Teatro Liberal, de 1909, centrado na Universidade Keiô) por Osanai Kaoru. Tsubouchi na verdade não foi reconhecido apenas pelo trabalho em teatro, mas também por ter modernizado a literatura japonesa em geral, focando especialmente nas produções de novelas e dramas. Ele traduziu muitos textos shakespearianos e foi editor do Waseda Bungaku, um dos jornais literários mais influentes da época. Além disso, foi considerado o fundador da chamada pesquisa teatral no Japão. No caso das traduções do teatro elisabetano, a sua intenção era reformar o kabuki, que ele considerava "o grande teatro japonês”. A sua idéia era aumentar o repertório de textos para kabuki. Da sua obra destaca-se a segunda peça, considerada pela crítica como a mais importante - En no gyôja $(O$ Eremita) foi publicada em várias versôes, mostrando uma influência muito grande de Ibsen.

Já a postura de Osanai Kaoru (18811928) era muito diferente. Ele pretendia romper com o passado, buscando um novo começo, inspirado em modelos do teatro ocidental contemporâneo. Ele não tinha interesse em dança e música, mantendo a sua atenção no texto, no drama psicológico. Gostava dos temas polêmicos. Os seus autores preferidos eram Ibsen, Maeterlinck e Pirandello. Tanto nas experiências de Tsubouchi quanto nas de Osanai, os atores de kabuki estavam sempre presentes. Mas o desenvolvimento de um método realista de atuar foi desenvolvido sobretudo a partir das experiências de Osanai (especialmente durante a turnê de 1912 a 1913). Ele experimentou o trabalho de Max Reinhardt em Berlim e o de Stanislavski em Moscou. Estes modelos passaram a fazer parte da sua investigação. A idéia era romper, do ponto de vista semântico, com temas universais de épocas imemoriais ou de um universo mitológico, dirigindo as questôes para o mundo moderno. Além do problema semântico, fazia-se presente uma discussão ontológica, ou seja, aquela que indagava qual a natureza daqueles corpos em cena e, mais do que isso, uma questão epistemológica, da ordem do conhecimento. Para lidar com os novos temas era preciso criar um novo corpo, buscando, o tempo inteiro, a identidade, ou seja, uma estabilidade que reconhecesse o corpo como singular.

Em linhas gerais, esse era um dilema e um desafio que permaneceria em experimentos diferentes. De 1924 a 1927, surgiu, por exemplo, o "pequeno teatro". Entre o terremoto de 1923 em Tóquio e a morte de Osanai Kaoru, em 1928 , nasceu o primeiro teatro totalmente dedicado ao shingeki. Hijikata Yoshi (1898-1959), que estava na Alemanha estudando os novos movimentos, voltou para Tóquio e iniciou o "pequeno teatro" em Tsukiji, uma área próxima a Ginza e distante do bairro de entretenimento onde eram realizados os primeiros shingeki. 
Com a mudança, o público tornou-se menor, no entanto mais consciente e atuante. O novo teatro era um laboratório de experiências, onde eram testados estilos ocidentais - do realismo ao expressionismo, do impressionismo ao simbolismo e a todas as novidades da vanguarda. A diferença em relação às experiências anteriores é que Hijikata estava mais interessado em um teatro político, e a entrada do pensamento marxista no mundo do shingeki não era bem vinda por muitos artistas. Hijikata encantou-se também com a técnica de Meyerhold que testava o trabalho corporal (biomecânica) e mensagens políticas. O rompimento com o estilo naturalista e realista, que prevalecia mesmo entre as companhias de esquerda, começou com a introdução do pensamento de Bertold Brecht, no começo dos anos 1950. Até hoje, a influência brechtiana é evidente, sendo percebida, por exemplo, no modo como os atores se dirigem ao público para falar, nas cançôes que interpretam e assim por diante.

Em 1960, nasceram as primeiras experiências com o teatro do absurdo e o rompimento com o teatro realista tornou-se uma prática corrente. Enquanto o shingeki buscava o seu lugar entre o teatro oficial japonês, a função de protesto e experimentações de vanguarda havia sido tomada pelo chamado teatro angura, que nasceu principalmente como um manifesto antiamericano, criando uma espécie de contracultura. A sua origem estava nos movimentos estudantis de esquerda (o Zengakuren, contra a renovação do Tratado de Segurança entre Japão e Estados Unidos nos anos 1960). No entanto, muitos grupos, incluindo o primeiro Seinengeijutsu de 1959, tiveram vida curta devido à falta de profissionalismo. Eles queriam chocar o público e não desenvolver uma técnica propriamente dita. Cinco grupos detacaram-se: Kurotento 68/71, Jôkyô Gekijô, Tenjô Sadiji, Tenkei Gekijô e Waseda Shôgekijô. Os teóricos do Kurotento (Teatro da Tenda Preta) foram Tsuno Kaitarô e Saeki Ryûkô. Eles conceituaram uma crítica contra o shingeki que era partilhada pela maioria dos grupos do angura. Para começar, ao invés de usar o proscênio, eles construíram, em 1970, uma grande tenda que abrigava uma espécie de palco. Ao invés de organizar as peças tradicionais de shingeki, com uma tendência quase sempre realista, eles mostravam inúmeras performances incluindo canções, danças, leituras, comédias, filmes, concertos etc. Eles também não atuavam apenas em Tóquio, viajando para muitas regiōes diferentes do Japão. Ao invés de preservar o culto ao teatro europeu, eles buscavam a criação de um teatro asiático, voltando a atenção para o nô e o kyôgen, e assimilando informaçōes de outros lugares países como a China, a Coréia, a Índia e as Filipinas.

Já o Jôkyô Gekijô, ou Teatro da Situação, girava em torno de seu carismático líder Kara Jûrô. Ainda vivo e ativo no Japão, Kara partiu do shingeki, mas inventou performances em muitos lugares inusitados, como banheiros públicos, estações de trem, etc. Ele foi um dos primeiros a usar a tenda para performance. A tenda vermelha no templo Hanazono, localizado em Shinjuku, tornou-se um símbolo da revolta contra abusos ambientais. Kara baseou-se muito no kabuki. Mas nas suas últimas produções, aparecem referências evidentes ao teatro brechtiano, aos personagens de videogames e dos quadrinhos japoneses (mangá). Excelente escritor, foi premiado com os prêmios Kishida e Akutagawa, respectivamente em 1969 e 1983, criando manuscritos para poucos. A complexidade de seu texto aparece no uso de diversas analogias e na ousada investigação de linguagem. Apenas quem conhece muito bem a língua japonesa pode perceber as nuances e trocadilhos propostos. Mais recentemente, começou a participar de produções comerciais, como outros artistas da vanguarda já haviam feito (o próprio Suzuki Tadashi é um exemplo).

O terceiro grupo, Tenjô Sajiki, dirigido por Terayama Shuji (1935-1983), produziu muitos trabalhos experimentais usando poesia, filme, fotografia, televisão, radio e até mesmo teatro para crianças. $\mathrm{O}$ seu teatro parecia um happening, com um visual que apostava no excesso de imagens e sons que o público mesmo 
produzia, participando das propostas. Embora tivesse a saúde muito debilitada, Shuji não parou de realizar eventos até a sua morte. Um desses eventos ficou muito famoso, porque as pessoas precisavam ir a diferentes lugares de Tóquio ao mesmo tempo. Mas a sua fama no exterior deveu-se principalmente ao estilo considerado "escandaloso". Muitas montagens lembravam as experiências realizadas no Living Theatre de Nova York, praticamente na mesma época.

A reação contra o dogma do realismo estrangeiro encontrou outro aliado importante em Ota Shôgo, fundador do Teatro da Transformação (Tenkei Gekijô), criado em 1968 e extinto em 1988 por completa inviabilidade financeira. Ota ficou muito famoso pela trilogia Estação Água, Estação Terra e Estação Vento. Também foi reconhecido como crítico e teórico. A marca de sua investigação amparava-se no silêncio, na pausa, na não-ação. Instruindo seus atores a trabalhar quase sem expressão facial e com movimentos extremamente lentos, Ota queria provocar a reflexão no público; a influência do nô era bastante evidente. Ele considerava a arte como algo difícil de ser conquistado. O seu poder estava na especialidade de uma atividade que não poderia ser praticada por qualquer um a qualquer momento.

De todos esses artistas, o mais conhecido entre nós é, sem dúvida, o diretor Suzuki Tadashi, do Waseda Shôgekijô, mais tarde conhecido como Companhia Suzuki de Toga. Famoso pela criação do seu método de preparação de atores chamado de "a gramática dos pés", trabalhou a partir da releitura das caminhadas típicas do $n \hat{o}$ (suriashi) e da relação entre os pés e o solo. Mas, de fato, não era só isso. Suzuki elaborou uma série de exercícios para explorar o trabalho corporal. O quadril tornou-se fundamental, mantendo sempre absoluta estabilidade, para que o trabalho pudesse evoluir. O que ainda caracterizava sobremaneira a sua investigação era o trabalho com a voz dos atores. O que parece importante perceber é como tudo estava integrado no corpo do ator. Ele não poderia trabalhar a voz sem preparar o corpo, especificamente os pés e o quadril. A preparação não acontecia partilhada em módulos, apenas na sua integralidade. Mas nada era tão evidente, uma vez que não se tratava apenas da aplicação de um método. Muitos tentaram aplicar os exercícios de Suzuki espelhando-se na famosa Shiraishi Kayoko, inclusive em Nova York e Los Angeles, onde a lista de estrelas de Hollywood encantava-se com os resultados cênicos apresentados por Suzuki. Mas não era tão fácil. E, de fato, nenhum outro ator chegou ao grau da maravilha de Shiraishi. Havia uma questão importante que estava relacionada às instruções e à implementação das mesmas.

O movimento angura foi considerado por alguns críticos como extinto em 1985. Alguns o classificaram como parte do shingeki, outros como uma espécie de pós-shingeki. Em alguns casos, ficou cada vez mais difícil perceber os limites entre as manifestações absolutamente comerciais e aquelas que buscavam um aprofundamento de questóes como a da identidade, a da formação do corpo do ator e assim por diante. Muitos diretores migraram de um gênero a outro, não raramente por questões financeiras e exigências de um mercado bastante complexo.

\section{A emergência do novo}

O Congresso organizado em Edinburgo em julho de 2001 sobre o Teatro Japonês no século XXI, colocou em cheque algumas dessas indagaçooes, expondo diferentes temas, como a organização em CD-ROM de modelos estéticos como o proposto pelo kyôgen (recentemente foi lançado um CD-ROM de kabuki animado, com uma relação explícita com filmes de ação americanos); a relação do nô com a contemporaneidade, algumas possibilidades de aplicação de princípios de Zeami na cena atual (fora do Japão); as novas relaçôes propostas, por exemplo, entre o mangá, o animé e as jovens performers japonesas; as montagens shakespereanas no Japão; a relação entre o teatro japonês e outras escolas ocidentais; e as experiências que têm ambicionado partir de "não modelos", como é 
o caso do grupo Gekidan Kaitaisha. Este grupo tem se apresentado em diferentes países do mundo, buscando contaminar o modo como organizam a cena e os corpos a partir das informaçōes dos novos ambientes onde se apresentam. A discussão acerca da emergência da arte e da linguagem, sobretudo no trânsito entre culturas distintas, suscita diferentes análises, mas há um dilema difícil de ser resolvido. No Japão, os estudos teatrais são normalmente hospedados em diferentes departamentos e não contam com um ensino específico. Fora do Japão, as análises são muitas vezes apenas históricas ou partem de pressupostos amparados por um modo muito distinto de entender o corpo, o pensamento e a arte. Surgem questões, mas dificilmente são aprofundadas. Pensar nas novas gerações de teóricos e artistas no Japão não significa necessariamente rever a influência de toda uma tradição como a do nô e a do kabuki. Muitos jovens diretores e críticos de teatro não têm qualquer curiosidade nem informação acerca do teatro tradicional japonês. A arte, para muitos desses jovens artistas, nada mais é do que um entre tantos outros objetos de consumo.

A pergunta que provavelmente suscita toda essa discussão remonta a indagaçóes que não pertencem apenas ao mundo contemporâneo e que são discutidas há séculos, não apenas pelos estudos da arte, mas pela própria filosofia. Nesse sentido, surgem interfaces com outras áreas do conhecimento para iluminar a discussão, partindo dos estudos do corpo. Estes não interessam apenas aos pesquisadores que buscam conhecer melhor o teatro japonês, mas a todos aqueles que estão testando novos protocolos experimentais para trabalhar o corpo do ator.

Neste panorama, a qualidade butô-sei, o corpo em crise proposto por Hijikata Tatsumi, traz também uma colaboração importante e cria a ponte com as discussões da primeira parte deste artigo. Durante os últimos quarenta anos, o butô japonês foi considerado um verdadeiro mistério. Os discípulos do seu criador Hijikata decidiram, após a sua morte em 1986, manter em segredo as chamadas "palavras do butô". O objetivo era evitar o processo de banalização que já havia começado com a chegada do butô ao Ocidente. Mas desde 1999, o silêncio começou a ser rompido com o lançamento, em inglês e japonês, do CD-ROM Butô Kaden (Butô, livro da flor), por Waguri Yukio, um dos discípulos de Hijikata que acompanhou toda a sua trajetória. Waguri explica que assim como o mentor do teatro nô japonês, Zeami, publicou os seus pensamentos em vários tratados, considerou também importante esclarecer os objetivos e o método de Hijikata.

Não bastasse esta surpresa, no mesmo ano, em Nova York, a revista The Drama Review publicou a tradução em inglês dos Mundos do Butô. São três textos do próprio Hijikata que datam dos anos 1960; uma entrevista com o coreógrafo, realizada pelo tradutor da obra de Marquês de Sade para o japonês, Shibusawa Tatsuhito (1928-1987); e uma conversa antológica entre Hijikata e o diretor de teatro Suzuki Tadashi. Conclusão: acabaram-se as desculpas e a aura de mistério que fez do butô o melhor pretexto dos últimos anos para acomodar toda $\mathrm{e}$ qualquer bobagem em nome do autoconhecimento, da exploração espiritual e do corpo degradado como palco de caretas e contorçôes.

Há muito material para ser estudado. Hijikata era um investigador do corpo, mas também um homem de muitas palavras. $\mathrm{O}$ volume de material escrito acerca de seus pensamentos e instruções é tão grande que no Centro de Arte da Universidade Keiô, em Tóquio, foi aberto em 2000 um arquivo com o seu nome, só para analisar os desdobramentos de sua obra no mundo contemporâneo ("Trabalhos Coletados de Hijikata").

$\mathrm{O}$ texto mais longo que deixou em vida (Yameru maihime, provisoriamente chamado Corpo Enfermo) está em processo de tradução e deverá ser publicado, também em inglês. Uma pergunta-chave que imediatamente apresentase é o que muda quando o corpo reencontra as palavras que registraram os seus movimentos. Para começar, sobra muito pouco butô no mundo 
contemporâneo, tanto no que se refere àqueles que tinham como objetivo copiar uma forma pronta de gestos, expressões e temporalidades, quanto para aqueles que estabilizaram padrōes de movimento e passam o resto de seus dias 'improvisando' repetições de uma fórmula que funcionou como material para as primeiras experimentações e não poderia ter sido engessada pela história. Em compensação, fica claro que o conceito-chave do butô, o corpo morto e o estado de crise, pode habitar outros ambientes e, desta forma, trabalhar com o que Hijikata chamava de "qualidade butô". Você pode ver um quadro e dizer "isso é butô", afirmava Hijikata. Nosso mundo não é um mundo dividido em gêneros, mas em familiaridades de pensamentos. Um estado de existência que não aparece apenas no corpo que dança, mas na literatura, nas artes visuais, no cinema e assim por diante. É um estado em que não se pode adivinhar o próximo passo. Não se trata de usar o corpo para alguma ação específica ou para causar algo (estranheza). Essa, dizia Hijikata: "é a idéia romântica ou uma espécie de depuração em que você tira algo de onde estava e reduz a gritos e choros, como em alguns happenings com uma total falta de precisão [...]. Dançar balé não é necessário para dançar butô, mas o balé é melhor do que algumas coisas que são feitas em nome da dança moderna”.

No texto Material Interior / Material (1960), Hijikata falava em rigor e ao mesmo tempo afirmava que não haveria como remover a ignorância e a miséria de suas danças. $\mathrm{O}$ sacrifício era a fonte de todo trabalho e todo dançarino era como uma criança ilegítima livre para experimentar essa qualidade. Ohara Akiko, uma das primeiras parceiras de Hijikata, do período em que ele ainda era um dançarino de jazz na Academia Ando (início dos anos 1950, em Tóquio), mora há quarenta anos no interior de São Paulo. Em duas longas conversas que tivemos, uma na comunidade onde vive e outra na companhia da crítica de dança e pesquisadora de butô Kuniyoshi Kazuko, a coreógrafa afirmou que o começo do ankoku butô (dança das trevas) era extremamente violento, e o conceito de sacrifício era levado às últimas conseqüências. Estudando a performance que é considerada a obra inaugural do butô no mundo, Kinjiki (título emprestado da obra de Mishima Yukio), o comentário de Ohara é facilmente confirmado. O espetáculo de morte e crueldade na verdade estava mais próximo da obra de Jean Genet do que do romance de Mishima (traduzido agora no Brasil pela Companhia das Letras) e buscava um novo corpo. Um corpo que treinava para que todos os tipos de movimento que viessem das juntas fossem deslocados, buscando um caminhar desarticulado, no qual uma perna precisava se esforçar para alcançar a outra. Essa desarticulação era também conceitual e deveria permear também os conceitos habituais. O balé, dizia Hijikata, parecia ter uma hierarquia que deixava o corpo no meio, deus acima e o inanimado abaixo. O dançarino de butô seria amparado pela perda da humanidade, suplantado pelo inanimado.

De certa forma, é como se a pele fosse virada pelo avesso, e esse espaço aparecesse em cena como algo que existe apenas como uma possibilidade. As palavras perdiam o seu caráter comunicativo, transformando-se em uma substância alienígena para criar um tipo de construção relacional. A função de comunicação, dizia, foi perdida pelo dia a dia. A palavra na obra de Hijikata, assim como na do diretor Suzuki Tadashi, é uma linguagem em suspensão que cria uma relação que expõe a substância humana. Este material que poderia "expor a substância humana”, ou seja, uma espécie de "pensamento encarnado", seria considerado por Hijikata como a notação dos movimentos, ou butoh fu, as palavras do butô. No CD-ROM, aparecem os sete mundos: do abismo, das flores, da neurologia, dos pássaros e bestas, dos muros, das pontes queimadas e da anatomia. Todos dizem respeito às qualidades dos movimentos e podem ser acompanhados a partir das palavras e dos chamados workshops em que aparece o tipo de movimento proposto por Hijikata, na maioria das vezes, interpretado por Waguri. É evidente que há um risco. Tal sistematização, por um 
lado, é um material importantíssimo para que seja entendida a proposta do criador. No entanto, este registro estará sempre sujeito à cópia por parte daqueles que entenderam erroneamente o butô como formas prontas, terapia de autoconhecimento, e não como processo.

Partindo da discussão proposta no início deste artigo e da investigação do próprio Hijikata, é preciso propor um cruzamento de domínios para levar a pesquisa adiante, sem restringi-la à análise de modelos estéticos da dança e do teatro ou, pior ainda, buscando um novo léxico para subverter o que já foi feito, criando uma simulação fictícia do estado de crise. $\mathrm{O}$ corpo em crise não busca um novo vocabulário para contrapor o antigo, mas deliberadamente abandona o conceito de vocabulário. Neste ano, a coleção Arts du spetacle (CNRS Editions), lançou a coleção Butô (s). O artigo "De Chair et de pensée: le butô et le surrealisme", de Miryam Sas, esclarece que Hijikata leu vários textos de Antonin Artaud, o que justifica a similaridade de propostas da dramaturgia da carne e do próprio corpo em crise. Para compreendê-los, mais do que a filosofia e a história da arte, proponho que a ciência é mais eficiente para elucidar o corpo imaginado por esses artistas. A ciência contemporânea elucida que seres humanos são criaturas da carne. Não são apenas mente ou espírito, e o corpo não é apenas uma casa. Nós somos a casa e não moramos nela. $\mathrm{O}$ que experimentamos e como damos sentido ao que experimentamos depende do tipo de corpos que temos e do modo como interagimos com os ambientes que habitamos. É através das interações corporais que vivemos no mundo e através do corpo que somos aptos a entender e agir no mundo com graus diversos de sucesso. Isso tudo vem antes da linguagem. Primeiramente não dependemos de proposições e palavras, mas de formas de entendimento enraizadas nos padrões de atividade corporal. Razão e conceituação estão embasadas na incorporação, quer dizer, nas orientações do corpo, nas manipulações e movimentos do modo como as açōes são postas no mundo. Só é possível conceituar usando sistemas emergentes da experiência corporal, e esta é a hipótese principal de Mark Johnson, coautor, ao lado de George Lakoff, do livro Philosophy in the Flesh (1999). Assim como aponta a tradutora de Hijikata para o inglês, Kurihara Nanako, Hijikata e seu butô-fu nada mais fazem além de reafirmar a hipótese desses novos filósofos-cientistas, trabalhando as chamadas "palavras encarnadas". Esta é a chave para entender o corpo em crise. Um corpo recheado por palavras, provando que há uma conexão entre estruturas da atividade corporal e o que pensamos como operações cognitivas superiores (raciocínio, atenção etc.). Ou seja, o modo como nos movimentamos e o modo como conceituamos o mundo não podem ser entendidos separadamente. É preciso mostrar como padróes de experiência corporal trabalham e se encarregam do entendimento e da razão dos nossos conceitos mais abstratos. As implicações filosóficas disso tudo mostram que não há mais lugar para a pessoa cartesiana com a mente separada do corpo. A maior parte do pensamento é inconsciente e a mente não é capaz de conhecer tudo a partir da auto-reflexão. A pessoa 'kantianamente' autônoma com uma razão transcendente que dita o que é moral e o que não é, também se torna fragilizada. A razão que emerge do corpo não pode transcendê-lo. Ela nasce do trânsito corpo/cérebro/ambiente. Se a razão é moldada pelo corpo, ela não é radicalmente livre porque os possíveis sistemas conceituais humanos e as formas possíveis de razão são limitados. Não há completa autonomia, nem um a priori baseado em um conceito universal de moralidade como queria Kant.

A pessoa 'fenomenológica', que buscava através da introspecção descobrir o que há para saber sobre a mente e a natureza da experiência, também se transforma em uma ficção. Na verdade, não temos um acesso direto consciente na maior parte do nosso tempo. A reflexão fenomenológica, embora tenha sido importantíssima para revelar a estrutura da experiência, depara-se com a pesquisa empírica do inconsciente cognitivo. Quanto à pessoa pós-estruturalista, 
totalmente relativa, puramente histórica, também deixa de existir. A mente é incorporada de modo a desenhar sistemas conceituais de acordo com o nosso corpo e os ambientes em que vivemos. A verdade é mediada pelo entendimento incorporado e pela imaginação. O corpo não é um suporte neutro, à espera das inscriçōes da história e da cultura. Tudo que nele é internalizado se modifica. O corpo faz a história assim como a história faz o corpo.

Não apenas na arte ocidental, mas também na filosofia, o corpo foi, durante anos, marginalizado como se comandado exclusivamente por uma razão soberana e um eu interior centralizador. A filosofia analítica foi fundada originalmente na idéia de que conceitos, proposições, formas lógicas, funções e todas as estruturas básicas do pensamento não têm virtualmente nada a ver com a natureza dos nossos corpos. $\mathrm{Na}$ lingüística, na lógica formal, e em algumas tradiçōes da inteligência artificial e da Ciência Cognitiva, a 'forma lógica' ou 'estrutura do conhecimento' tem sido vista como uma estrutura dos signos (seqüência de letras) que são sem significado em si mesmos e precisam ser interpretados para ter um significado. Essa interpretação parte da associação de um signo com uma coisa ou categoria do mundo (ou dentro de um conjunto de modelos teóricos do mundo). Tal formato de signos para coisas no mundo ou para um modelo matemático é tanto desincorporado quanto literal. É desincorporado porque o corpo não tem papel constituinte na caracterização da natureza do significado. É literal porque não é mediado por qualquer mecanismo imaginativo como imagens mentais, metáforas, protótipos etc. Para dar um exemplo simplificado de como essa visão clássica trabalha, considera-se a sentença "A cadeira é verde". Para as teorias clássicas de significado, haveria um conceito "cadeira" definido por uma lista de propriedades e condiçôes necessárias e suficientes para algo ser cadeira. Cada uma dessas categorias é supostamente definida em termos de propriedades de objetos existentes no mundo que são estruturados independentemente de qualquer percepção humana. O conceito verde seria parte de um sistema de conceitos de cor (diferente de vermelho ou azul). O sistema seria uma coleção estruturada de signos, sem significado neles mesmos, que seriam significativos quando associados a categorias de cor no mundo. Não é o corpo que dá significado às cores nessas teorias, mas a estrutura de signos e a conexão do sistema de signos com o mundo externo. É precisamente este quadro de significados que os primeiros cientistas cognitivos chamaram de representações internas da realidade externa.

$\mathrm{Na}$ dança ocidental, durante anos, a significação e a categorização de movimentos também conferiu a tônica dos espetáculos, assim como outros estudiosos olhavam a mente como desincorporada e usavam a razão para ser literal. Raciocinar era a manipulação de estruturas proposicionais (um conceito lógico). Não é à toa que este pensamento fundou a metáfora da mente como um programa de computador, sem papel para a incorporação humana na estrutura de conceitos e raciocínio. Por isso, até a última década, ninguém estudava as Ciências Cognitivas para entender a importância da incorporação humana. Ao invés disso, pesquisadores buscavam a recuperação do corpo através de movimentos pós-modernos e da fenomenologia. No entanto, nenhuma dessas abordagens produziu uma pesquisa adequada para o papel do corpo na conceituação e no raciocínio. A fenomenologia, por definição, foca exclusivamente no nível fenomenológico de descrição e análise, não dando nenhuma atenção aos níveis neurofisiológicos e do inconsciente cognitivo. Embora a sociologia pós-moderna e a teoria literária enfatizem o corpo como sendo marginalizado e suprimido da nossa experiência cultural, elas tendem a ver o corpo como social e cultural, construído como texto, ignorando o fato de existirem constrangimentos corporais naquilo que experimentamos, conceituamos e raciocinamos sobre.

A segunda geração de cientistas cognitivos converge várias disciplinas empíricas que mostram 
como nossos sistemas conceituais e os raciocínios que fazemos são embasados em padrões de atividade corporal. Essa nova ciência presta atenção especial à neurobiologia, já que vê a razão como definida pelas estruturas do cérebro e do corpo juntas nas suas interaçôes com o ambiente e outras pessoas. Na mente incorporada, a razão abstrata não é separada do sistema sensório-motor, mas ao invés disso, o constrói. A experiência sensório-motora é esquematizada como em esquemas de imagem e esquemas motores (puxar, empurrar, mover). Nossos conceitos mais abstratos são desenvolvidos como extensões metafóricas dessas estruturas básicas sensório-motoras, e nossa razão abstrata envolve inferências que são basicamente projeções de inferências sensório-motoras.

Hijikata e Artaud jamais estudaram as Ciências Cognitivas. Muitos cientistas que dis- cutem a incorporação sequer desconfiam da existência da qualidade butô ou do corpo morto proposto por Hijikata, e nada sabem acerca do teatro da crueldade. No entanto, há um sentido de crise que permeia o deslocamento da razão soberana frente à possibilidade de explorar o corpo em seus estados de existência - aqueles em que a vida insinua-se apenas como uma possibilidade. Uma entre tantas outras extravagâncias barrocas que a natureza propôs, como pontuou o ultradarwinista Richard Dawkins. Seguir os resíduos de um corpo em crise pode conduzir a lugar nenhum. Mas o que existe, então, no limite extremo? - perguntava Mishima, para em seguida responder roubando, uma vez mais, as palavras da carne dilacerada: "Nada existe, quem sabe, a não ser umas fitas flutuando no vazio".

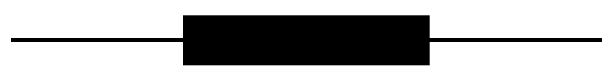

\section{Referências bibliográficas}

ASLAN, O. Butô (s). Paris: CNRS, 2002.

BRANDSTETTER, Gabriele; VÖLCKERS, H. Re-Membering the Body. Viena: Hatje Cantz Publishers, 2000.

CLARK, Andy. Being there, putting brain, body and world together again. Boston: MIT Press, 1997.

FOSTER, Susan Leigh. Corporealities, dancing knowledge, culture and power. Routledge, 1996.

GREINER, C. Butô, pensamento em evolução. Escrituras, 1998.

JOHNSON, M.; LAKOFF, G. Philosophy in the Flesh: the Embodied Mind and its Challenge to Western Thought. Basic Books. 1999.

NANCY, Jean-Luc. Corpus. Arche, 2000.

TATSUMI, Hijikata. Inner Material/Material. TDR, Boston, v. 165, Spring 2000. Fragments of Glass: A conversation between Hijikata and Suzuki. TDR, Boston, v. 165, Spring 2000. 